\title{
Expression and clinical significance of microRNA-21, maspin and vascular endothelial growth factor- $C$ in bladder cancer
}

\author{
HUI-HUI ZHANG ${ }^{1}$, FAN $^{2}{ }^{2}$, YOU-HAN CAO ${ }^{1}$, XIONG-BING ZU ${ }^{2}$ and MIN-FENG CHEN ${ }^{2}$ \\ ${ }^{1}$ Department of Urology, The First Affiliated Hospital of University of South China, Hengyang, Hunan 421001; \\ ${ }^{2}$ Department of Urology, Xiangya Hospital, Central South University, Changsha, Hunan 410008, P.R. China
}

Received October 2, 2014; Accepted June 22, 2015

DOI: $10.3892 / 01.2015 .3540$

\begin{abstract}
The present study aimed to explore the expression and clinical significance of microRNA-21 (miR-21), maspin and vascular endothelial growth factor C (VEGF-C) in bladder cancer (BC). A total of 53 BC samples and 12 normal bladder tissue samples were collected. Total messenger RNA (mRNA) was extracted, and reverse transcription-quantitative polymerase chain reaction (RT-qPCR) was used to evaluate the expression of miR-21 and maspin in BC and normal bladder tissues. Immunohistochemistry was used for the detection of maspin and VEGF-C protein expression. Furthermore, the correlations between these molecules and certain clinicopathological parameters were investigated, and survival analysis was performed to assess their prognostic significance. miR-21 mRNA expression and VEGF-C protein expression were increased in $\mathrm{BC}$ tissues compared with those in normal bladder tissues, whereas maspin mRNA and protein expression levels in $\mathrm{BC}$ tissues were significantly decreased $(\mathrm{P}<0.01)$. miR-21, maspin and VEGF-C expression were significantly associated with the stage, grade and lymph node metastasis of $\mathrm{BC}(\mathrm{P}<0.05)$, but not the other clinicopathological features evaluated. There was a marked inverse correlation between the mRNA expression of miR-21 and maspin, with a coefficient of $-0.978(\mathrm{P}<0.001)$. Similarly, there was a significant inverse correlation between the protein expression of maspin and VEGF-C, with a coefficient of $-0.589(\mathrm{P}<0.001)$. Overexpression of miR-21 and VEGF-C, as well as decreased maspin expression, were associated with a poorer prognosis. These results suggested that upregulation of miR-21, decreased maspin expression and enhanced VEGF-C in $\mathrm{BC}$ may promote tumor progression. miR-21, maspin and VEGF-C may therefore have significant roles as biomarkers for prognosis and as therapeutic targets of $\mathrm{BC}$.
\end{abstract}

Correspondence to: Professor You-Han Cao, Department of Urology, The First Affiliated Hospital of University of South China, 69 Chuanshan Road, Hengyang, Hunan 421001, P.R. China

E-mail: nanhuacaoyouhan@163.com

Key words: microRNA-21, maspin, vascular endothelial growth factor $\mathrm{C}$, bladder cancer

\section{Introduction}

Bladder cancer (BC) is one of the most prevalent malignancies worldwide, with $\sim 70,980$ novel cases diagnosed and 14,330 mortalities occurring in the United States in 2008 alone (1). In China, BC represents the most common cancer of the urinary tract. Furthermore, $\sim 70 \%$ of patients initially diagnosed with superficial BC, and therefore are not in a life-threatening situation, develop a minimum of one recurrence within 5 years (2). In addition, $20 \%$ of BC patients with recurrence experience disease progression (3). Thus, identification of novel biomarkers for prognosis and therapeutic targets of $\mathrm{BC}$ will help to advance clinical diagnosis and treatment of this disease.

MicroRNAs (miRNAs) are single-stranded, non-coding RNAs that are hypothesized to regulate gene expression at the post-transcriptional level (4). The dysregulation of miRNAs has been found to be associated with cancer initiation and progression, suggesting that miRNAs may be used as molecular biomarkers for the diagnosis of cancer and prediction of prognosis. miRNA-21 (miR-21) has been reported to be overexpressed in multiple human solid tumors, including BC (5-8). In addition, miR-21 has been proven to suppress the expression of genes involved in the development of tumors. For example, it has been revealed that maspin is a target gene of miR-21, and upregulation of miR-21 promotes downregulation of maspin, inducing tumor progression (9).

In a previous proteomic study by our group (10), maspin was identified as a potential vascular endothelial growth factor C (VEGF-C)-associated protein in T24 BC cells. In another study (11), promoter DNA methylation of maspin was identified in T24 BC cells. The mRNA and protein expression levels of maspin were increased in a dose-dependent manner in T24 cells, following treatment with increasing concentrations of DNA methyltransferase inhibitor 5-Aza-2'-deoxycytidine (5-Aza-CdR). The proliferation, migration and invasion of cells were significantly inhibited following treatment with increasing concentrations of 5-Aza-CdR, while the levels of apoptosis were markedly increased. Furthermore, these effects were associated with decreased expression of VEGF-C. These results therefore suggested a potential role for maspin in the regulation of VEGF-C in BC.

Based on these results, it was hypothesized that miR-21, maspin and VEGF-C may have significant roles in the 
development of BC. However, to the best of our knowledge, a comprehensive study regarding the expression status and clinical relevance of miR-21, maspin and VEGF-C in $\mathrm{BC}$ is not currently available. Therefore, the present study aimed to compare the expression profiles of miR-21, maspin and VEGF-C in BC and normal tissues, and investigate the potential diagnostic and prognostic value of these molecules.

\section{Materials and methods}

Patients and samples. The present study was approved by the Ethics Review Board of The First Affiliated Hospital of University of South China (Hengyang, China) and Xiangya Hospital (Changsha, China). Informed consent was obtained from all patients. The present study evaluated BC specimens, including cancer lesions, from 53 patients who had undergone surgical resection at The First Affiliated Hospital of University of South China and Xiangya Hospital between 2005 and 2012. No patient had received preoperative adjuvant therapy. All samples were treated in an identical manner following surgical removal, and were immediately snap-frozen in liquid nitrogen and stored at $-80^{\circ} \mathrm{C}$ prior to RNA extraction. The patients included 35 males and 18 females with ages ranging from 32 to 84 years (median age, 57 years). In addition, 12 normal bladder specimens were obtained from male patients with benign prostatic hypertrophy undergoing transurethral resection (age range, 65-78 years; median age, 70 years), which were used as the control. Information regarding the clinicopathological factors, including age, histological grade, tumor stage, tumor number, tumor diameter, lymph node status and recurrence status were also collected. Telephone follow-ups were performed every 3 months post surgery to evaluate patient survival status. The final follow-up date included in the present study was December 31, 2013.

Reverse transcription-quantitative polymerase chain reaction (RT-qPCR) analysis of miR-21 and maspin expression. Total RNA was extracted from the frozen tissue samples using TRIzol reagent (Invitrogen Life Technologies, Carlsbad, CA, USA). miR-21-specific primers (forward, 5'-ACGTTGTGTAGCTTATCAGACTG-3' and reverse, 5'-AATGGTTGTTCTCCACACTCTC-3') were purchased from Ambion (Applied Biosystems Life Technologies, Foster City, CA, USA) and the internal control RNU6B gene was purchased from Wuhan Boster Biological Technology (Wuhan, China). Complementary DNA (cDNA) synthesis was performed using the High Capacity cDNA Synthesis kit (Applied Biosystems Life Technologies) with miRNA specific primers. An Applied Biosystems 7500 Real-time system (Applied Biosystems Life Technologies) with miRNA specific primers by TaqMan Gene Expression Assay (Applied Biosystems Life Technologies) was used to perform RT-qPCR.

The PCR cycling conditions were as follows: $95^{\circ} \mathrm{C}$ for $10 \mathrm{~min}, 40$ cycles of $95^{\circ} \mathrm{C}$ for $15 \mathrm{sec}, 60^{\circ} \mathrm{C}$ for $1 \mathrm{~min}$ and $72^{\circ} \mathrm{C}$ for $30 \mathrm{sec}$, and a final extension of $72^{\circ} \mathrm{C}$ for $10 \mathrm{~min}$. Fluorescent signals from each sample were measured at the endpoint of each cycle. The expression of miR-21 was normalized to the internal RNU6B control and plotted as relative values. The fold change in miR-21 expression between the samples and normal control was calculated using the $2^{-\Delta \Delta \mathrm{Ct}}$ method (9). RT-qPCR was performed in triplicate for each sample.

For the evaluation of maspin expression in patient samples, RT-qPCR was used to measure maspin mRNA expression levels. GAPDH (Wuhan Boster Biological Technology) served as a control. TaqMan probes for maspin and GAPDH were obtained from Applied Biosystems. The primer sequences used were as follows: Maspin forward, 5'-GGTGGGGATTCCATAGAGGT-3' and reverse, 5'-AATCGGCATCCACAGAAAAG-3'; GAPDH forward, 5'-CAATGACCCCTTCATTGACC-3' and reverse, 5'-GACAAGCTTCCCGTTCTCAG-3'. PCR cycling conditions consisted of: $95^{\circ} \mathrm{C}$ for $5 \mathrm{~min}$, followed by 40 cycles of $94^{\circ} \mathrm{C}$ for $20 \mathrm{sec}, 59^{\circ} \mathrm{C}$ for $20 \mathrm{sec}$ and $72^{\circ} \mathrm{C}$ for $20 \mathrm{sec}$, then $72^{\circ} \mathrm{C}$ for $5 \mathrm{~min}$ and finally $55^{\circ} \mathrm{C}$ for $10 \mathrm{sec}$. The expression of maspin mRNA was calculated relative to GAPDH expression levels using the $2^{-\Delta \Delta C t}$ method.

Immunohistochemistry. Prior to histopathological examination, all specimens were fixed in $10 \%$ formaldehyde solution (Guanghua Sci-Tech Co., Ltd., Guangdong, China). Sections (4- $\mu \mathrm{m})$ of formalin-fixed paraffin-embedded tissues were cut with a microtome (SYD-S2020; Yude Electronic Instrument Co., Ltd., Shenyang, China) and dried at $37^{\circ} \mathrm{C}$ overnight on silanized slides for immunohistochemical staining for VEGF-C and maspin protein. Subsequently, samples were deparaffinized with xylene (Guanghua Sci-Tech Co., Ltd.) at room temperature for $80 \mathrm{~min}$, washed with a graded ethanol/water mixture and then washed with distilled water. Endogenous peroxidase activity was blocked using $0.3 \%$ hydrogen peroxide (Sangon Biotech Co., Ltd, Shanghai, China) solution for $20 \mathrm{~min}$. For antigen retrieval, the sections were soaked and heated in citrate buffer $(0.01 \mathrm{~mol} / \mathrm{l}$; Dingguo Changsheng Biotech Co., Ltd, Beijing, China), microwaved for $20 \mathrm{~min}$, washed three times with distilled water and then blocked with $1 \%$ bovine serum albumin (Dingguo Changsheng Biotech Co., Ltd.) at room temperature for 30 min. Rabbit anti-human VEGF-C (cat. no. BA0548) and mouse anti-human maspin (cat. no. PB0311) polyclonal antibodies (1:100; Wuhan Boster Biological Technology) were used as the primary antibodies, according to the manufacturer's instructions. Subsequently, sections were incubated with goat anti-polyvalent antibody (cat. no. BA1011; 1:3,000; Wuhan Boster Biological Technology) at $37^{\circ} \mathrm{C}$ for $10 \mathrm{~min}$ and then streptavidin peroxidase (cat. no. BA1088; 1:300; Wuhan Boster Biological Technology) at $37^{\circ} \mathrm{C}$ for $10 \mathrm{~min}$. Slides were visualized using diaminobenzidine and counterstained with hematoxylin (Sangon Biotech Co., Ltd.) prior to observation. The addition of the primary antibodies was omitted in the negative control. Immunostaining of invasive ductal breast carcinoma and benign prostate tissue sections, obtained from patients with breast cancer and benign prostatic hyperplasia, respectively, who had undergone surgical resection at The First Affiliated Hospital of University of South China and Xiangya Hospital between April 2005 and October 2012, were considered to be positive controls for VEGF-C and maspin, respectively.

Ten distinct areas containing tumor cells were evaluated randomly for each slide, under a low-power microscopy field (BX51; Olympus Corporation, Tokyo, Japan), by two experi- 


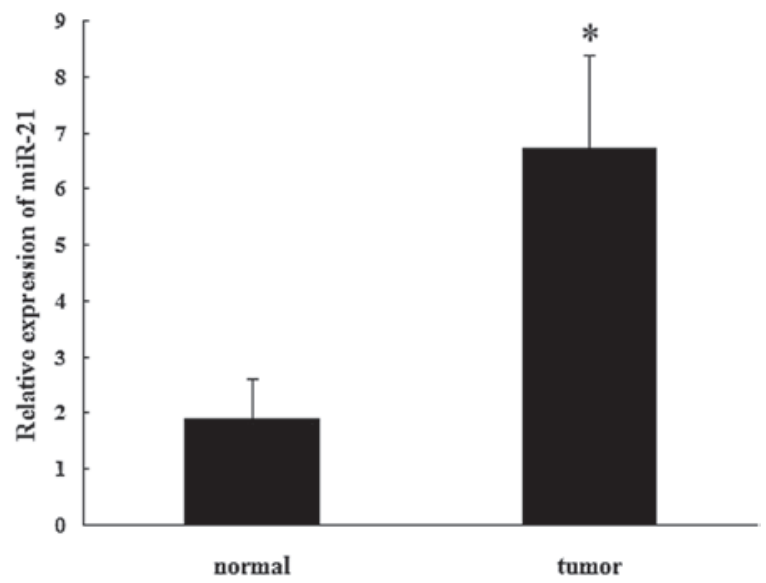

Figure 1. miR-21 expression is upregulated in patients with BC, compared with that of normal controls. Reverse transcription-quantitative polymerase chain reaction analysis was used to evaluate the messenger RNA expression levels of miR-21 in BC and normal tissues. Values are expressed as the mean \pm standard deviation. ${ }^{*} \mathrm{P}<0.01$. miR-21, microRNA-21; BC, bladder cancer.

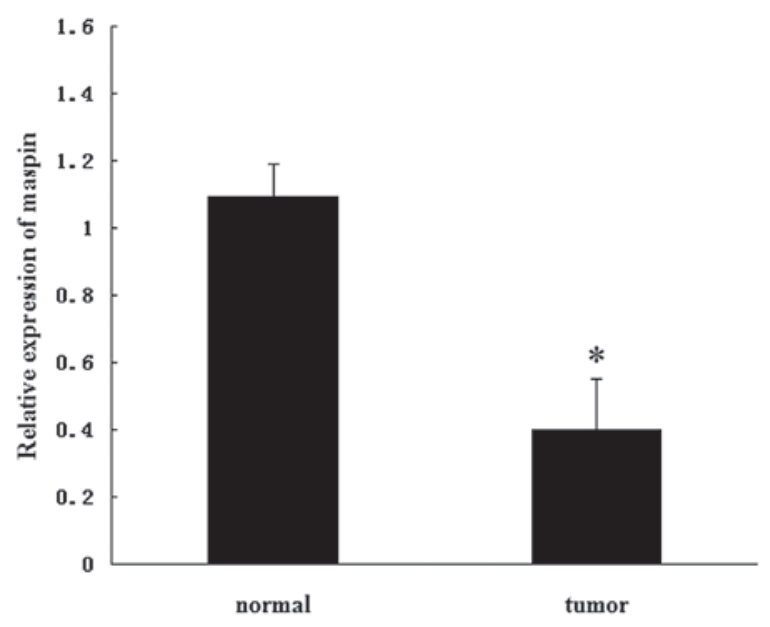

Figure 2. Maspin expression is downregulated in patients with BC, compared with that of normal controls. Reverse transcription-quantitative polymerase chain reaction analysis was used to evaluate the expression of maspin messenger RNA in BC and normal tissues. Values are expressed as the mean \pm standard deviation. ${ }^{*} \mathrm{P}<0.01$. BC, bladder cancer.

enced independent investigators without prior knowledge of patient disease status; $\geq 100$ tumor cells were examined per field. Two scoring systems were used to evaluated the staining intensity and percentage of positive cells in each specimen. The staining intensity was scored on a semiquantitative 4-point scale: 0 , equivalent to the negative control; 1 , weak cytoplasmic and nuclear staining slightly darker than the negative control; 2 , moderate staining defined as an intensity of score 1-3; and 3 , intense staining equivalent to or darker than the positive control. The percentage of stained cells was also scored on a semiquantitative 4 -point scale: $0,<10 \% ; 1,10-25 \% ; 2$, $25-50 \%$; and $3,>50 \%$. Finally, the scores for staining intensity and percentage of stained cells were combined and defined as follows: $0-1,-; 2,+; 3-4,++$; and $5-6,+++$.

Statistical analysis. Statistical analyses were performed using SPSS software version 13.0 (SPSS, Inc., Chicago, IL,
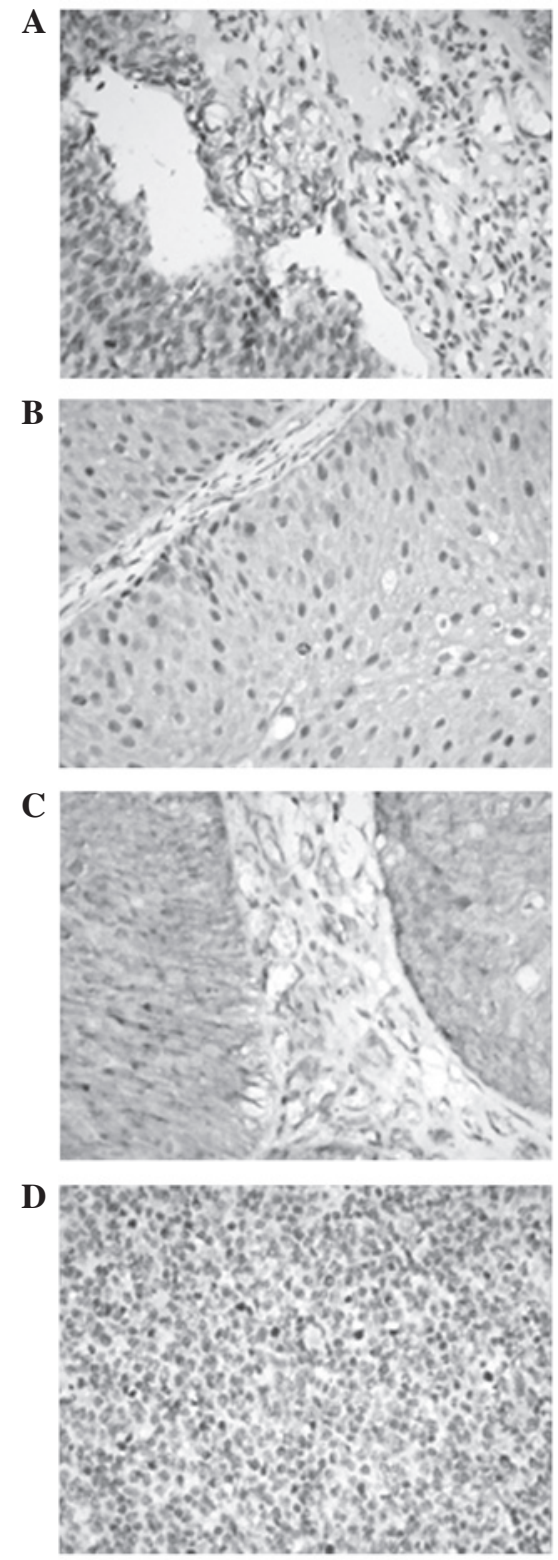

Figure 3. Immunohistochemical analysis of maspin and VEGF-C protein expression in bladder cancer tissues. Transitional epithelium from bladder cancer tissues with (A) negative VEGF-C expression and (B) positive VEGF-C expression. Transitional epithelium from normal tissues with (C) negative maspin expression and (D) positive maspin expression. VEGF-C, vascular endothelial growth factor C.

USA). Clinical data were analyzed using the $\chi^{2}$ test or the Mann-Whitney $U$ test. The associations between data were evaluated using Spearman's rank correlation test. Kaplan-Meier curves were constructed, and the log-rank test was performed for analysis of survival data. Multivariate analysis of the prognostic factors was performed with a Cox regression model. The results are expressed as the mean \pm standard deviation. $\mathrm{P}<0.05$ was considered to indicate a statistically significant difference.

\section{Results}

mRNA expression of miR-21 is upregulated and maspin is downregulated in BC. RT-qPCR analysis was used to evaluate expression levels of miR-21 in $53 \mathrm{BC}$ and 12 normal bladder specimens. Consistent with the results of previous studies $(6,8)$ 
Table I. Expression of maspin and VEGF-C in BC and normal bladder tissues.

\begin{tabular}{lcccccc}
\hline Group & $\mathrm{n}$ & $\begin{array}{c}\text { VEGF-C } \\
\text { positive }\end{array}$ & $\begin{array}{c}\text { VEGF-C } \\
\text { negative }\end{array}$ & P-value & $\begin{array}{c}\text { Maspin } \\
\text { positive }\end{array}$ & $\begin{array}{c}\text { Maspin } \\
\text { negative }\end{array}$ \\
\hline BC & 53 & 37 & 16 & 0.018 & 23 & 30 \\
Normal & 12 & 4 & 8 & & 7 & 5 \\
\hline
\end{tabular}

VEGF-C, vascular endothelial growth factor C; BC, bladder cancer.

Table II. Correlation between VEGF-C, maspin and miR-21 expression with the clinicopathological factors of patients with bladder cancer.

\begin{tabular}{|c|c|c|c|c|c|c|c|c|c|c|}
\hline \multirow[b]{2}{*}{ Characteristic } & \multirow[b]{2}{*}{$\mathrm{n}$} & \multicolumn{2}{|c|}{ VEGF-C } & \multirow[b]{2}{*}{ P-value } & \multicolumn{2}{|c|}{ Maspin } & \multirow[b]{2}{*}{ P-value } & \multicolumn{2}{|c|}{ miR-21 } & \multirow[b]{2}{*}{ P-value } \\
\hline & & $+/++/+++$ & - & & $+/++/+++$ & - & & High & Low & \\
\hline Gender & & & & 0.721 & & & 0.912 & & & 0.776 \\
\hline Male & 35 & 25 & 10 & & 15 & 20 & & 18 & 17 & \\
\hline Female & 18 & 12 & 6 & & 8 & 10 & & 10 & 8 & \\
\hline Age & & & & 0.319 & & & 0.758 & & & 0.833 \\
\hline$<60$ years & 22 & 17 & 5 & & 9 & 13 & & 12 & 10 & \\
\hline$\geq 60$ years & 31 & 20 & 11 & & 14 & 17 & & 16 & 15 & \\
\hline Tumor diameter & & & & 0.241 & & & 0.583 & & & 0.523 \\
\hline$<3 \mathrm{~cm}$ & 30 & 19 & 11 & & 14 & 16 & & 17 & 13 & \\
\hline$\geq 3 \mathrm{~cm}$ & 23 & 18 & 5 & & 9 & 14 & & 11 & 12 & \\
\hline Tumor stage & & & & 0.013 & & & 0.035 & & & 0.012 \\
\hline $\mathrm{T} 1-\mathrm{T} 2$ & 33 & 19 & 14 & & 18 & 15 & & 13 & 20 & \\
\hline T3-T4 & 20 & 18 & 2 & & 5 & 15 & & 15 & 5 & \\
\hline Tumor grade & & & & 0.006 & & & 0.001 & & & 0.037 \\
\hline G1-G2 & 28 & 15 & 13 & & 18 & 10 & & 11 & 17 & \\
\hline G3 & 25 & 22 & 3 & & 5 & 20 & & 17 & 8 & \\
\hline Tumor number & & & & 0.231 & & & 0.119 & & & 0.563 \\
\hline Single & 17 & 10 & 7 & & 10 & 7 & & 8 & 9 & \\
\hline Multiple & 36 & 27 & 9 & & 13 & 23 & & 20 & 16 & \\
\hline Occurrence & & & & 0.430 & & & 0.194 & & & 0.089 \\
\hline Primary & 19 & 12 & 7 & & 6 & 13 & & 13 & 6 & \\
\hline Recurrence & 34 & 25 & 9 & & 17 & 17 & & 15 & 19 & \\
\hline Lymph node & & & & 0.013 & & & 0.007 & & & 0.012 \\
\hline Negative & 33 & 19 & 14 & & 19 & 14 & & 13 & 20 & \\
\hline Positive & 20 & 18 & 2 & & 4 & 16 & & 15 & 5 & \\
\hline
\end{tabular}

VEGF-C, vascular endothelial growth factor C; miR-21, microRNA-21.

increased levels of miR-21 were detected in BC tissues, compared with those of the normal tissues, with a 6.71-fold mean increase ( $\mathrm{P}<0.01$; Fig. 1). The BC patients were subsequently divided into high ( $>6.71$-fold) or low ( $<6.71$-fold) miR-21 expression groups, accordingly. By contrast, decreased maspin mRNA expression levels were detected in BC tissues, compared with those of normal tissues $(0.40 \pm 0.15$ vs. $1.09 \pm 0.10 ; \mathrm{P}<0.01$; Fig. 2$)$. A negative correlation between miR-21 and maspin mRNA expression was identified using the Spearman's rank correlation test, with a correlation coefficient of $-0.978(\mathrm{P}<0.05)$.
Protein expression of maspin is reduced and VEGF-C is enhanced in $B C$. Immunohistochemical analysis was used to detect the expression of maspin and VEGF-C protein in $\mathrm{BC}$ and normal bladder samples. Representative examples of tissue reactivity for maspin and VEGF-C are displayed in Fig. 3. As indicated in Table I, 43.4\% (23/53) cases of BC and $58.3 \%$ (7/12) of normal tissues were positive for maspin expression. VEGF-C expression was positive in $69.8 \%$ (37/53) cases of BC and 33.3\% (4/12) of normal tissues. These results indicated that the maspin protein expression was 

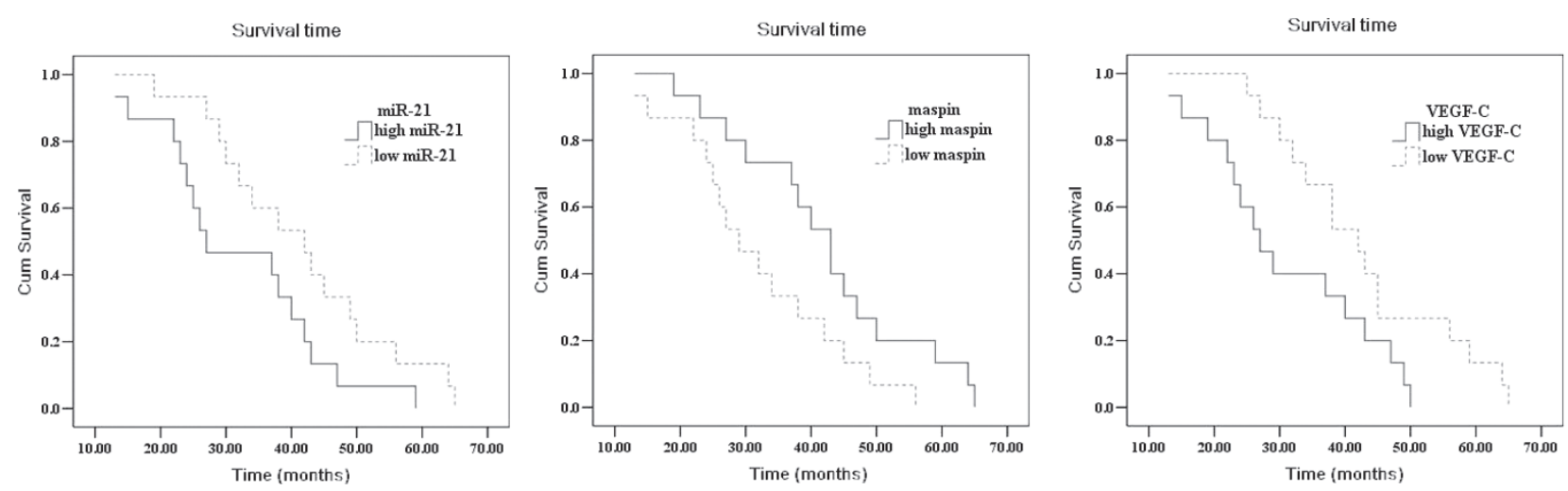

Figure 4. Kaplan-Meier survival curves of miR-21, maspin and VEGF-C expression for bladder cancer patients. miR-21, microRNA-21; VEGF-C, vascular endothelial growth factor C; Cum, cumulative.

significantly decreased in $\mathrm{BC}$ tissues, compared with that of normal tissues, whereas VEGF-C protein expression was increased. There was a negative correlation between maspin and VEGF-C protein expression, detected by the Spearman's rank correlation test, with a correlation coefficient of -0.589 $(\mathrm{P}<0.01)$.

Associations between miR-21, maspin and VEGF-C mRNA expression and clinicopathological factors. The associations between the expression of mir-21, maspin and VEGF-C with gender, age, tumor diameter, tumor stage, tumor grade, tumor number, tumor occurrence and lymph node metastasis status were subsequently analyzed. As shown in Table II, miR-21, maspin and VEGF-C expressions were significantly associated with tumor stage, tumor grade and lymph node metastasis (all $\mathrm{P}<0.05$ ). However, there was no correlation between miR-21 expression and any other clinicopathological factors evaluated, including gender, age, tumor diameter, tumor number and recurrence.

Significance of miR-21, maspin and VEGF-C expression in $B C$ prognosis. Survival analysis of 53 BC patients was conducted using information available on clinical follow-up. Kaplan-Meier survival analysis revealed that patients with high miR-21 and VEGF-C expression and/or low maspin expression had significantly poorer independent survival times compared with patients with low miR-21 and VEGF-C expression and high maspin expression $(\mathrm{P}<0.01)$. Fig. 4 exhibits the survival curves of patients with various miR-21, maspin and VEGF-C expression statuses. The mean postoperative survival times of the low and high miR-21 groups were 59.8 \pm 6.4 and $42.8 \pm 5.1$ months, respectively; of the low and high maspin groups were 40.0 \pm 5.3 and $62.6 \pm 5.6$ months, respectively; and of the low and high VEGF-C group were $60.7 \pm 6.6$ and $41.9 \pm 4.6$ months, respectively. The multivariate Cox regression model revealed that high miR-21 and VEGF-C expression and low maspin expression $[\mathrm{P}=0.018$; hazard ratio (HR), 3.32; 95\% confidence interval (CI), 1.16-4.74; $\mathrm{P}=0.005$; HR, 2.08; 95\% CI, 1.42-2.66; $\mathrm{P}=0.037$; HR, 2.19; 95\% CI, 1.45-3.86, respectively] were significantly unfavorable prognostic factors, in addition to lymph node metastasis status $(\mathrm{P}=0.024$; HR, 3.05 ; 95\% CI, 2.63-4.17).

\section{Discussion}

$\mathrm{BC}$ is one of the most common malignancies of the urinary system. According to current guidelines, patients with $\mathrm{BC}$ are typically treated with surgical resection followed by intravesical chemotherapy (12). Although therapeutic intervention frequently induces disease remission, there is significant variance in clinical outcomes between patients. Furthermore, few diagnostic and predictive biomarkers are currently available for $\mathrm{BC}$, highlighting the importance of enhancing understanding of the underlying molecular mechanisms in order to improve the prevention, diagnosis and treatment of BC.

Studies have increasingly focused on the role of miRNAs in human cancer. miRNAs are suggested to have regulatory activities in a broad range of developmental processes, and have been implicated in a diverse range of diseases, including various types of cancer (13). In the present study, RT-qPCR analysis indicated that miR-21 expression was upregulated in $\mathrm{BC}$ tissues compared with that of normal bladder tissues. In particular, miR-21 has been shown to be involved in various cancer-associated processes, including cell growth, invasion and apoptosis (14). miR-21 induces hepatocellular carcinoma HepG2 cell proliferation via the suppression of mitogen-activated protein kinase-kinase 3 (15). In addition, miR-21 promotes oral cancer invasion via the $\mathrm{Wnt} / \beta$-catenin pathway by targeting DKK2 (16). Furthermore, certain miRNA expression profiling studies have demonstrated that, concurrently with the results of the present study, miR-21 is upregulated in $\mathrm{BC}(6,8,17)$. Therefore, a potential role for miR-21 as an oncogene has been suggested.

Studies have indicated that miR-21 is able to target multiple tumor suppressor genes, including TPM1 and PTEN $(18,19)$. To date, maspin has also been identified as a target gene of miR-21 (20). Maspin, a member of the serine protease inhibitor superfamily, has been shown to function as a tumor suppressor to inhibit cell invasion and metastasis in various cancer cells (21). In prostate cancer, maspin suppresses prostate tumor metastases by inhibiting the urokinase-type plasminogen activator (uPA)/uPA receptor axis and angiogenesis (22). Low maspin expression levels are closely associated with the liver metastasis of colorectal adenocarcinoma, potentially via degradation of the extracellular matrix-tenascin to enhance carcinoma cell mobility (23). In 2008, Zhu et al (20) 
demonstrated that suppression of miR-21 in MDA-MB-231 metastatic breast cancer cells significantly inhibited their invasion and lung metastasis. The expression of maspin is inversely correlated with miR-21 expression in human breast tumor specimens (20). Ali et al (24) also demonstrated that maspin was significantly decreased in four drug-resistant prostate cancer cell lines, which was a result of the increased expression of miR-21 in the aggressive, drug-resistant cell lines. These results indicate the potential regulation of maspin by miR-21 in such tumors. In the present study, a negative correlation was identified between miR-21 and maspin mRNA expression in $\mathrm{BC}$, which corroborated the results of the above studies. The results of the present study suggested that upregulation of miR-21 may result in decreased maspin mRNA expression and may be closely associated with the pathogenesis of BC. However, Torres et al (25) identified an association between increased maspin expression and upregulation of miR-21 in endometrial cancer, suggesting distinct and tissue-specific associations between these molecules in various types of malignancy, which requires further study in order to reveal its clinical relevance.

VEGF-C is a member of the VEGF family, which regulates lymphatic system formation under physiological and pathological conditions via its specific receptor, VEGFR-3 (26). Since VEGF-C is a specific lymphangiogenic factor, its expression is upregulated in various human malignancies and is typically associated with lymphatic metastasis and poor prognosis $(27,28)$. In the present study, the expression of VEGF-C was significantly increased in BC tissues, compared with that of normal tissues, in agreement with the results of aforementioned previous studies. In a previous proteomic study by our group (10), maspin was identified as a potential VEGF-C-associated protein in T24 BC cells. Maspin was demonstrated to be involved in the regulation of VEGF-C in T24 BC cells by another further study (11). Therefore, the association between VEGF-C and maspin expression was evaluated using Spearman's rank correlation test in the present study. As expected, the data revealed a negative correlation between maspin and VEGF-C expression, providing histological evidence for the role of maspin in the regulation of VEGF-C.

In order to assess the clinical significance of the expression of miR-21, maspin and VEGF-C in patients with BC, the associations between these factors and various clinicopathological parameters, including prognosis, were evaluated. miR-21, maspin and VEGF-C expression levels were significantly associated with tumor stage, tumor grade and lymph node metastasis (all $\mathrm{P}<0.05$ ); while there was no correlation detected between their expression and the other clinicopathological factors evaluated, including gender, age, tumor diameter, tumor number and recurrence. Survival analysis demonstrated that overexpression of miR-21 and VEGF-C, as well as downregulation of maspin were significantly associated with a poorer prognosis. These results indicated that miR-21, maspin and VEGF-C may be promising candidates for use as diagnostic and prognostic molecular biomarkers for BC.

In conclusion, although the expression profiles of miR-21, maspin and VEGF-C have been identified in numerous types of human malignancy, elucidation of the roles of these factors in $\mathrm{BC}$ carcinogenesis requires further characterization. To the best of our knowledge, the present study is the first comprehensive report regarding the expression status and clinical relevance of miR-21, maspin and VEGF-C in BC. The present study revealed that maspin was downregulated, while VEGF-C was overexpressed in BC tissues compared with normal tissues. This finding was associated with the simultaneous upregulation of miR-21 expression, which had previously been demonstrated to be a major regulator of maspin expression. Furthermore, high expression of miR-21 and VEGF-C, as well as a low expression of maspin, was associated with decreased postoperative survival times of patients with $\mathrm{BC}$, independent of lymph node metastasis and other clinicopathological factors. Based on these results, although direct evidence is lacking, it was hypothesized that as a tumor suppressive miRNA, miR-21 functions through regulation of maspin and VEGF-C, suggesting a miR-21/maspin/VEGF-C pathway in BC. However, further studies are required to verify the results presented in the present preliminary study.

\section{Acknowledgements}

The present study was supported by the Natural Science Foundation of Hunan Province (no. 11JJ2040) and the National Natural Science Foundation of China (nos. 81272838 and 81202005).

\section{References}

1. Jemal A, Siegel R, Ward E, Hao Y, Xu J and Thun MJ: Cancer statistics, 2009. CA Cancer J Clin 59: 225-249, 2009.

2. Quek ML, Stein JP, Clark PE, Daneshmand S, Miranda G, Cai J, Groshen S, Lieskovsky G, Quinn DI, Raghavan D, et al: Natural history of surgically treated bladder carcinoma with extravesical tumor extension. Cancer 98: 955-961, 2003.

3. Babjuk M, Oosterlinck W, Sylvester R, Kaasinen E, Böhle A and Palou-Redorta J; European Association of Urology (EAU): EAU guidelines on non-muscle-invasive urothelial carcinoma of the bladder. Eur Urol 54: 303-314, 2008.

4. Visone R and Croce CM: MiRNAs and cancer. Am J Pathol 174: 1131-1138, 2009

5. Griffiths-Jones S, Saini HK, van Dongen S and Enright AJ: miRBase: Tools for microRNA genomics. Nucleic Acids Res 36: D154-D158, 2008.

6. Neely LA, Rieger-Christ KM, Neto BS, Eroshkin A, Garver J, Patel S, Phung NA, McLaughlin S, Libertino JA, Whitney D, et al: A microRNA expression ratio defining the invasive phenotype in bladder tumors. Urol Oncol 28: 39-48, 2008.

7. Volinia S, Calin GA, Liu CG, Ambs S, Cimmino A, Petrocca F, Visone R, Iorio M, Roldo C, Ferracin M, et al: A microRNA expression signature of human solid tumors defines cancer gene targets. Proc Natl Acad Sci USA 103: 2257-2261, 2006.

8. Wszolek MF, Rieger-Christ KM, Kenney PA, Gould JJ, Silva Neto B, Lavoie AK, Logvinenko T, Libertino JA and Summerhayes IC: A MicroRNA expression profile defining the invasive bladder tumor phenotype. Urol Oncol 29: 794-801, 2009.

9. Jajoo S, Mukherjea D, Kaur T, Sheehan KE, Sheth S, Borse V, Rybak LP and Ramkumar V: Essential role of NADPH oxidase-dependent reactive oxygen species generation in regulating microRNA-21 expression and function in prostate cancer. Antioxid Redox Signal 19: 1863-1876, 2013.

10. Zhang HH, Qi F, Zu XB, Cao YH, Miao JG, Xu L and Qi L: A proteomic study of potential VEGF-C-associated proteins in bladder cancer T24 cells. Med Sci Monit 18: BR441-BR449, 2012.

11. Zhang H, Qi F, Cao Y, Zu X, Chen M, Li Z and Qi L: 5-Aza-2'-deoxycytidine enhances maspin expression and inhibits proliferation, migration and invasion of the bladder cancer T24 cell line. Cancer Biother Radiopharm 28: 343-350, 2013. 
12. Babjuk M, Burger M, Zigeuner R, Shariat SF, van Rhijn BW, Compérat E, Sylvester RJ, Kaasinen E, Böhle A, Palou Redorta J and Rouprêt M; European Association of Urology: EAU guidelines on non-muscle-invasive urothelial carcinoma of the bladder: Update 2013. Eur Urol 64: 639-653, 2013.

13. Ambros V: The functions of animal microRNAs. Nature 431: 350-355, 2004.

14. Fu X, Han Y, Wu Y, Zhu X, Lu X, Mao F, Wang X, He X, Zhao $Y$ and Zhao Y: Prognostic role of microRNA-21 in various carcinomas: A systematic review and meta-analysis. Eur J Clin Invest 41: 1245-1253, 2011.

15. Xu G, Zhang Y, Wei J, Jia W, Ge Z, Zhang Z and Liu X: MicroRNA-21 promotes hepatocellular carcinoma HepG2 cell proliferation through repression of mitogen-activated protein kinase-kinase 3. BMC Cancer 13: 469, 2013.

16. Kawakita A, Yanamoto S, Yamada S, Naruse T, Takahashi H, Kawasaki G and Umeda M: MicroRNA-21 promotes oral cancer invasion via the $\mathrm{Wnt} / \beta$-catenin pathway by targeting DKK2. Pathol Oncol Res 20: 253-261, 2013.

17. Guancial EA, Bellmunt J, Yeh S, Rosenberg JE and Berman DM: The evolving understanding of microRNA in bladder cancer. Urol Oncol 32: e31-e40, 2013.

18. Meng F, Henson R, Wehbe-Janek H, Ghoshal K, Jacob ST and Patel T: MicroRNA-21 regulates expression of the PTEN tumor suppressor gene in human hepatocellular cancer. Gastroenterology 133: 647-658, 2007.

19. Zhu S, Si ML, Wu H and Mo YY: MicroRNA-21 targets the tumor suppressor gene tropomyosin 1 (TPM1). J Biol Chem 282: 14328-14336, 2007.

20. Zhu S, Wu H, Wu F, Nie D, Sheng S and Mo YY: MicroRNA-21 targets tumor suppressor genes in invasion and metastasis. Cell Res 18: 350-359, 2008.

21. Bodenstine TM, Seftor RE, Khalkhali-Ellis Z, Seftor EA, Pemberton PA and Hendrix MJ: Maspin: Molecular mechanisms and therapeutic implications. Cancer Metastasis Rev 31: 529-551, 2012.
22. McGowen R, Biliran H Jr, Sager R and Sheng S: The surface of prostate carcinoma DU145 cells mediates the inhibition of urokinase-type plasminogen activator by maspin. Cancer Res 60: 4771-4778, 2000

23. Zheng H, Tsuneyama K, Cheng C, Takahashi H, Cui Z, Murai Y, Nomoto K and Takano Y: Maspin expression was involved in colorectal adenoma-adenocarcinoma sequence and liver metastasis of tumors. Anticancer Res 27: 259-265, 2007.

24. Ali S, Almhanna K, Chen W, Philip PA and Sarkar FH: Differentially expressed miRNAs in the plasma may provide a molecular signature for aggressive pancreatic cancer. Am J Transl Res 3: 28-47, 2010.

25. Torres A, Torres K, Paszkowski T, Radej S, Staśkiewicz GJ, Ceccaroni M, Pesci A and Maciejewski R: Highly increased maspin expression corresponds with up-regulation of miR-21 in endometrial cancer: A preliminary report. Int J Gynecol Cancer 21: 8-14, 2011.

26. Su JL, Yen CJ, Chen PS, Chuang SE, Hong CC, Kuo IH, Chen HY, Hung MC and Kuo ML: The role of the VEGF-C/VEGFR-3 axis in cancer progression. Br J Cancer 96: 541-545, 2007.

27. DeMei M, XiangXin L, YongPing X, YongXia Y, YunHai Y and Lin Z: Vascular endothelial growth factor $\mathrm{C}$ expression is closely correlated with lymph node recurrence and poor prognosis in patients with early stage cervical cancer. J Int Med Res 41: 1541-1549, 2013.

28. Zhang Y, Meng X, Zeng H, Guan Y, Zhang Q, Guo S, Liu X and Guo Q: Serum vascular endothelial growth factor-C levels: A possible diagnostic marker for lymph node metastasis in patients with primary non-small cell lung cancer. Oncol Lett 6: $545-549,2013$ 